\title{
Spatial analysis of salinity distribution patterns in upper layers of the Black Sea
}

\author{
Denis Krivoguz ${ }^{1}{ }^{*}$, Sergei Mal'ko ${ }^{2}$, and Anna Semenova ${ }^{2}$ \\ ${ }^{1}$ Azov-Black Sea branch of VNIRO (“AzNIIRKH”), 344002, Rostov-on-Don, Russian Federation \\ ${ }^{2}$ Kerch State Maritime Technological University, 298309, Kerch, Russian Federation
}

\begin{abstract}
Salinity is one of the most important factors that primarily determines the level of seawater's density and, consequently, the movement of water masses in the World Ocean. Spatial distribution of the salinity in different layers of the Black Sea are associated with varying levels of water balance seasonal variability and, general circulation of Black Seas waters and in the surface layer has a seasonal structure. To study spatial distribution of salinity in upper layers of the Black Sea we've used data from Copernicus Marine Environment Monitoring Service, that were processed and aggregate by seasons and depth. We found that the most fluctuated layer is a top layer (up to $2.8 \mathrm{~m}$ ) and the highest values Black Sea salinity reaches near the Bosporus Strait, where more saline water from the Sea of Marmara connected with fresher water of the Black Sea. Also we found that the impact of the river flows, mixing of the water, water regime of the sea decreasing with depth, so in the bottom of the upper layer the spatial fluctuation of the salinity is minimal and reaches about $\pm 3 \%$, while in the depth of $2.8 \mathrm{~m}$ its reaches $\pm 12-15 \%$. The lowest level of salinity through all of the upper layer $(0-50 \mathrm{~m})$ lays around the seashore and north-western part of the sea.
\end{abstract}

\section{Introduction}

One of the most significant environmental factors in aquatic ecosystems has always been water salinity [1]. In general, it is the least studied of all the variables that characterize the oceans or climate, mainly due to a lack of historical data. This is primarily due to the fact that until recently, our knowledge of the distribution of salinity in the oceans was based on inconsistent measurements [2,3].

Salinity can be defined as the sum of inorganic salts, dissolved in one cubic decimetre of water [4].

Its influence on the formation and existence of any marine and coastal ecosystems is also significant. In some cases, it can act as a limiting factor, as a result of anthropogenic or natural impact.

For marine organisms, any significant changes in the physio-chemical regime of the waterbody are not favourable [2]. Many marine and freshwater organisms living in Black Sea basins show a significant decrease in their size. For example, in the molluscs Mytilus

\footnotetext{
${ }^{*}$ Corresponding author: krivoguz d o@azniirkh.ru
} 
edulis and Cerastoderma edule, which live at a salinity of about 2-6\%, their shells are approximately 2-4 times smaller in size than in the samples of these species in Kiel Bay, where salinity is about $15 \%$ [4].

The freshwater molluscs Theodoxus fluvialitis and Bithynia tentaculata in the Baltic Sea are much smaller than in freshwater bodies. It is possible that a decrease in size in marine species is associated with a reduction in their life expectancy in salty waters. For example, the life expectancy of the molluscs from Cardiidae family in the North Atlantic is about 9 years, while in the Sea of Azov they live no more than 5 years.

It should also be noted that freshwater and marine organisms placed in salty waters, where salinity can reach $40 \%$, consumption of oxygen is significantly increases. Mytilus edulis and Acartia tonsa, when they placed in diluted seawater, the level of oxygen consumption increases in 2.0-2.5 times [5].

Many halobionts are extremely euryhaline. For example, some algae from Protoroa family are completely indifferent to changes in salinity from fresh water to hypersaline. Artemia salina lives at salinity from 16 to $270 \%$ [5].

The beginning of measurements of salinity in the Black Sea dates back to 1890 and continues to this day. Regular observations have been made since the 50s of the 20th centuries. The main problem inherent in them is the unevenness of the temporal and spatial distribution.

Belokurov and Shokurova [1] note that in the Black Sea there are various trends of long-term variability of salinity, especially in its upper layer - 0-50 m.

The long-term changes noted by the authors [6] on the surface and upper layer are characterized by a change from the period of increased salinity in 1966-1975 for a period of lower salinity. The average value of the salinity decreases in this period, according to the authors, was about $0.22 \%$ [7]. On the other hand, they noticed an increase in salinity at all horizons of the main pycnocline. After the period 1961-1970, it ranged from $0.14 \%$ at a depth of $300 \mathrm{~m}$ and up to $0.33 \%$ at a depth of $100 \mathrm{~m}$.

Belokopytov [8] notes that the patterns of the seasonal cycle in salinity changes qualitatively when moving from the sea surface to a layer of constant halocline. In the $0-20$ $\mathrm{m}$ layer, the dual-core structure of saline reserve with maximum at the centres of large-scale cyclonic cycles is characteristic of the winter - spring period. At the same time, in the summer, with the general desalination of the sea and the weakening of its circulation, local maximum become weakly expressed, while the entire central part of the sea becomes more homogeneous region.

In the autumn period, the saline reserve maximum shifts to the region of the eastern cyclonic cycle. In the 20-75 m layer, the dual-core structure of saline reserve prevails in the summer period. In the rest of the year, spatial distribution is typical with an eastern maximum of saline stock [9].

The layer of constant pycnocline is characterized by the summer prevalence of maximum saline reserve in the western cyclonic cycle.

Thus, changes in the nature of the spatial distribution of the salinity in different layers of the Black Sea are associated with varying levels of water balance seasonal variability and, general circulation of Black Seas waters.

\section{Research area}

The Black Sea is an inland sea that belongs to the basin of the Atlantic Ocean. In the southwest it is connected with the Sea of Marmara by the Bosphorus Strait, and in the northeast with the Sea of Azov by the Kerch Strait [6,10]. Also, the Black Sea is one of the largest and deepest inland seas. Its maximum depth reaches the mark of 2258 meters (Figure 1). The total area of the Black Sea is $420325 \mathrm{~km}^{2}$, and with the Sea of Azov $-462000 \mathrm{~km}^{2}$. 


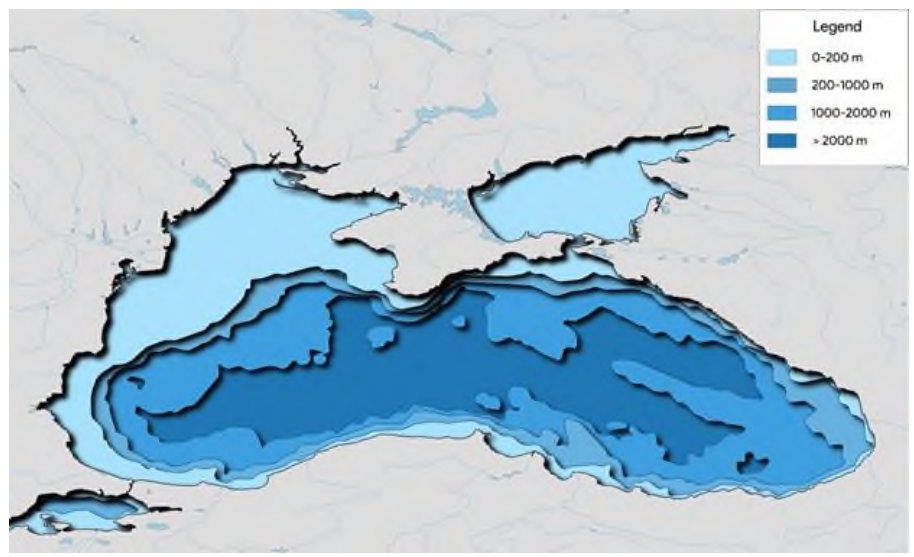

Fig. 1. Bathymetric map of the Black Sea.

The average seasonal cycle of geostrophic circulation in the Black Sea (according to Ivanov and Belokopytov [8]):

- from January to March - a single cyclonic rotation cantered in the eastern part of the sea, the western circulation is weakly expressed;

- from April to May - a single cyclonic rotation with a centre in the western part of the sea, the eastern cycle is weakly expressed;

- from June to July - two cycles, the western more intense;

- from August to September - two cycles, the eastern one is more intense;

- from October to December - two cycles of equal intensity.

About $80 \%$ of the river flow is concentrated in the north-western part of the Black Sea.

The Caucasian rivers contribute about $13 \%$ to the input part of the water balance of the sea, while the runoff from Turkey is about $7 \%$. The contribution of the rivers of the Crimean Peninsula is insignificant.

The largest river, flowing into the Black Sea is the Danube. It receives water from such rivers like Inn, Drava, Tisza, Sava, Morava, Seret and Prut. The Danube on average annually brings about $203 \mathrm{~km}^{3}$ of fresh water to the Black Sea. The Danube catchment basin is about 817 thousand $\mathrm{km}^{2}$ [11].

Another large river flowing into the Black Sea is the Dnieper. Its catchment basin is slightly smaller compared to the Danube and amounts to 503 thousand $\mathrm{km}^{2}$. The level of water flown by the Dnieper into the water balance of the Black Sea is largely affected by its strong regulation [6]. The third largest river, that flows into the Black Sea is the Rioni, which is located on the Caucasian coast of the Black Sea. Each year, it contributes $13 \mathrm{~km}^{3}$ of fresh water collected from the catchment basin.

According to the characteristics of the formation and characteristics of the sea water the Black Sea can be divided into surface with salinity up to $18 \%$, intermediate and deep. The surface water circulation of the sea is cyclonic. Two large central cycles in the eastern and western parts of the sea stand out. The flow velocity increases from $10 \mathrm{~cm} / \mathrm{s}$ in the centre to $25 \mathrm{~cm} / \mathrm{s}$ at the periphery of these cycles. With depth, the current velocities quickly decay to $100 \mathrm{~m}$ depth [12]. Average salinity is about $18 \%$, near estuaries - less than $9 \%$. In the open part of the sea, salinity increases with depth from $17-18 \%$ on the surface to $22.3 \%$ at the bottom. An important feature of the hydrological structure of sea waters is the existence of a constant halocline between horizons of 90-120 m. Salinity in this depth interval increases from 18.5 to $21.5 \%$.

The total volume of river runoff and precipitation that falls into the Black Sea exceeds the evaporation of water from it by more than a third part. Deep water is more saline than 
the water of the surface layer, due to the influx of salt water into the Black Sea from the Mediterranean Sea through the Bosphorus Strait. The combination of these factors leads to the fact that the Black Sea shows a clear vertical stratification by salinity. There is also an upper layer of water with a lower level of salinity, which lies above the deep layer with more saline water. The permanent halocline in the Black Sea is located at a depth of 120$200 \mathrm{~m}$. The salinity in the upper layer varies depending on the season. Salinity at the sea surface reaches its maximum values in winter (18.2\% in December), subsequently decreasing to the minimum summer value (17.6\%o in August).

\subsection{Data}

We used the monthly averaged salinity distribution data from Copernicus Marine Environmental Monitoring Service (CMEMS) - Black Sea Reanalysis from 1992 to 2019. The quality of the model data, as well as the model itself, improve with increasing of in-situ observations numbers (Table 1).

Table 1. Salinity misfit EANs for time period 1995-2015 (left) and time period 2005-2015 (right) [13].

\begin{tabular}{|c|c|c|}
\hline Salinity & BIAS & RMS \\
\hline $0-100 \mathrm{~m}$ & $-0.014 / 0.002$ & $0.33 / 0.26$ \\
\hline $100-300 \mathrm{~m}$ & $-0.006 / 0.009$ & $0.19 / 0.15$ \\
\hline $300-800 \mathrm{~m}$ & $-0.005 /-0.002$ & $0.05 / 0.03$ \\
\hline
\end{tabular}

Salinity data gathered by using microwave radiometer (remote sensing techniques) or by in-situ measurements (by profiling floats or moored buoys).

\section{Results and discussion}

The spatial distribution of salinity in the Black Sea in the surface layer has a seasonal structure (Figure 2). So, in the cold season, from October to March, the distribution of salinity is the same for almost all of the entire territory of the Black Sea and is about $18 \%$. In the warm season, from April to September, some of the fresh water zones can be seen, mainly in the eastern and central parts. This is primarily due to the active flow of fresh water from Turkish rivers in the south and Georgian rivers in the southeast, as well as due to the seasonal cycle of geostrophic water circulation.

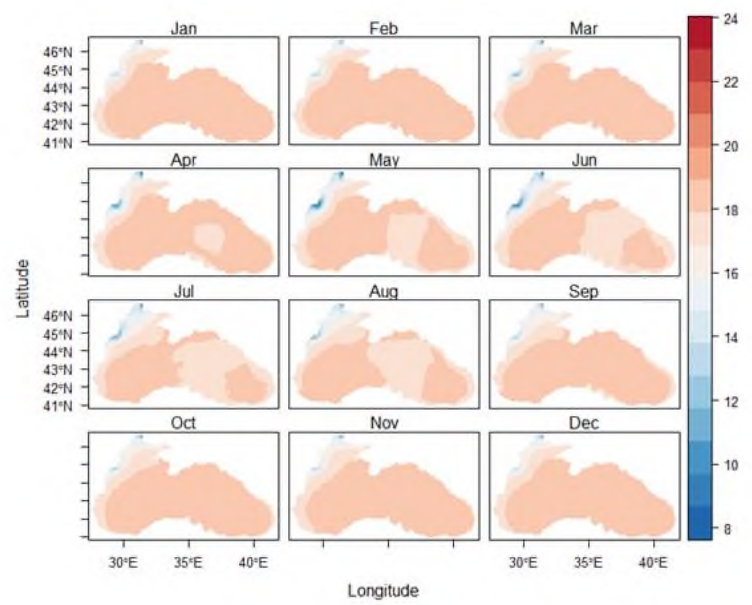

Fig. 2. Spatial distribution of salinity in $2.8 \mathrm{~m}$ depth. 
The highest salinity levels occur locally throughout the year and are spatially located in the southwest of the sea, near the Bosporus Strait, where the Black Sea is exchanged with the more saline water. In general, the range of variation in salinity in the Black Sea is in the range from 8.5 to $23.5 \%$. It should also be noted the north-western part of the Black Sea, where due to the activities of the Dniester and the Danube, large-scale desalination occurs throughout the western coast. Such a spatial distribution of areas with low salinity is local, which reflects the median of the variational series of salinity of the surface layer (Table 2).

Table 2. Statistical values of monthly distribution of salinity in $2.8 \mathrm{~m}$ depth.

\begin{tabular}{|c|c|c|c|c|c|c|c|c|c|c|c|c|}
\hline & Jan & Feb & Mar & Apr & May & Jun & Jul & Aug & Sep & Oct & Nov & Dec \\
\hline Min & 11.34 & 11.24 & 10.47 & 8.86 & 8.63 & 9.5 & 10.36 & 11.05 & 11.04 & 10.97 & 10.94 & 11.18 \\
\hline 1-st quartile & 18.05 & 18.1 & 18.1 & 17.85 & 17.7 & 17.63 & 17.63 & 17.74 & 17.89 & 17.92 & 17.96 & 18.02 \\
\hline Median & 18.16 & 18.17 & 18.12 & 18.02 & 17.92 & 17.87 & 17.85 & 17.87 & 17.97 & 18.04 & 18.09 & 18.13 \\
\hline 3-rd quartile & 18.23 & 18.23 & 18.18 & 18.1 & 18.01 & 18.01 & 17.98 & 18.00 & 18.07 & 18.11 & 18.14 & 18.19 \\
\hline Max & 22.05 & 21.86 & 21.89 & 22.15 & 21.9 & 22.14 & 22.65 & 22.88 & 23.01 & 22.64 & 22.52 & 22.26 \\
\hline
\end{tabular}

At a depth of 28 meters, seasonal fluctuations are less visible compared to the surface layer, but can also be seen. In the warm period, the level of salinity drops down in April and May, as well as in July, and located approximately in the eastern and central parts of the sea.

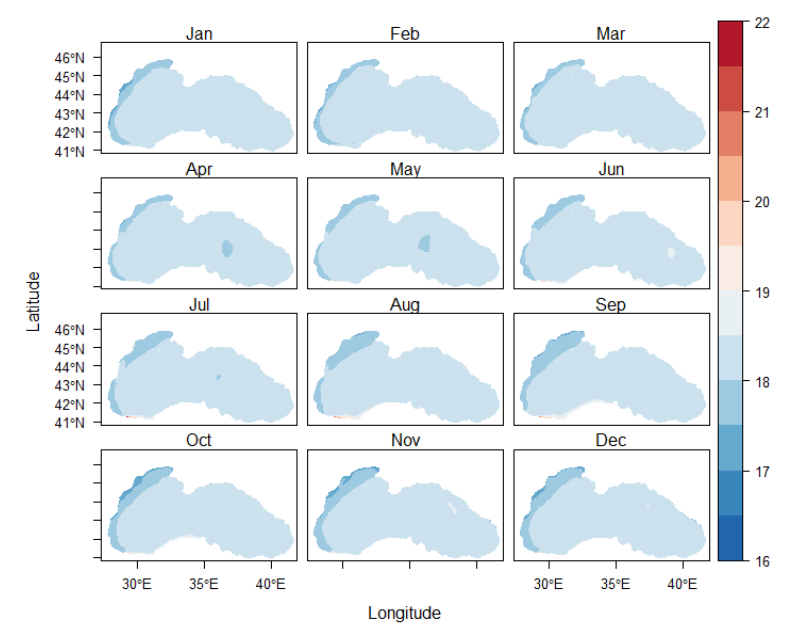

Fig. 3. Spatial distribution of salinity in $28 \mathrm{~m}$ depth.

Also, we should note the spatial similarity of the locations of these fluctuations with the surface layer, which indicates the genesis of these descensions associated with the processes of vertical mixing of waters.

As well as on the surface layer, we can see significant decreases of salinity levels in the western and north-western parts to $16 \%$. Local maximum is also located in the Bosporus Strait, where salinity in June-September reaches 21-23\%o (Table 3).

Table 3. Statistical values of monthly distribution of salinity in $28 \mathrm{~m}$ depth.

\begin{tabular}{|c|c|c|c|c|c|c|c|c|c|c|c|c|}
\hline & Jan & Feb & Mar & Apr & May & Jun & Jul & Aug & Sep & Oct & Nov & Dec \\
\hline Min & 16.96 & 17.2 & 17.25 & 17.36 & 17.46 & 17.59 & 17.5 & 17.38 & 17.34 & 16.93 & 17.05 & 17.01 \\
\hline 1-st quartile & 18.15 & 18.18 & 18.17 & 18.17 & 18.20 & 18.2 & 18.16 & 18.17 & 18.16 & 18.16 & 18.16 & 18.14 \\
\hline Median & 18.22 & 18.24 & 18.23 & 18.24 & 18.24 & 18.26 & 18.26 & 18.23 & 18.24 & 18.26 & 18.26 & 18.22 \\
\hline 3-rd quartile & 18.29 & 18.29 & 18.29 & 18.30 & 18.30 & 18.31 & 18.32 & 18.29 & 18.31 & 18.34 & 18.32 & 18.29 \\
\hline Max & 22.08 & 21.89 & 21.91 & 22.16 & 21.91 & 22.17 & 22.69 & 22.91 & 23.04 & 22.66 & 22.55 & 22.3 \\
\hline
\end{tabular}


At a depth of 49 meters, the situation is opposite, compared with the upper layers. Here in winter, in the eastern part of the sea, more saline waters rise from deeper layers. The difference in salinity is approximately 1-1.5 \%o. In warmer period, from May to November, due to active water exchange with the Sea of Marmara, occurs a significant decrease in salinity in the southwestern part of the sea to $21-22 \%$. In general, the median salinity level at this depth is $18.5-19 \%$ and is slightly differentiated depending on the changing seasons, being approximately at the same level.

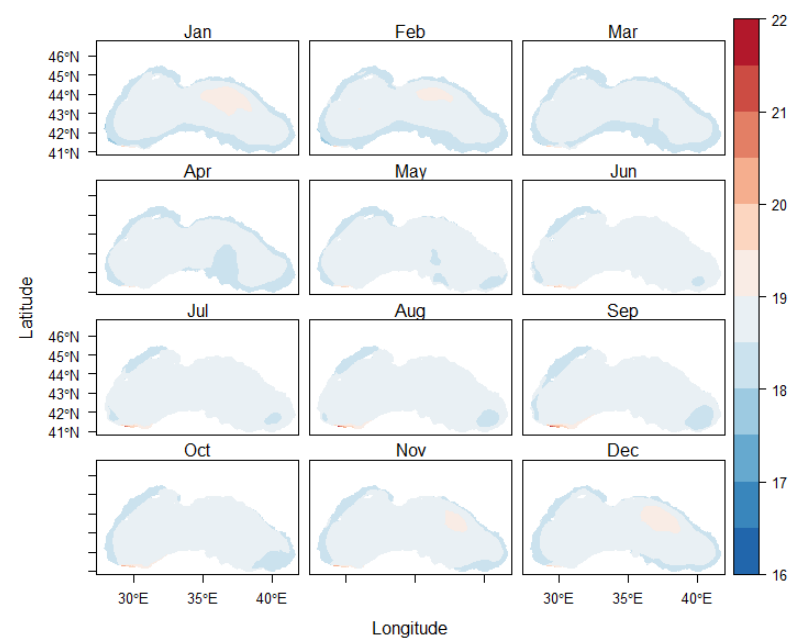

Fig. 4. Spatial distribution of salinity in $49 \mathrm{~m}$ depth.

The minimum salinity level is about $17 \%$, confined to coastal areas throughout the sea. In the warmer period occurs a slight increase in salinity, which leads to the achieving the average values for this layer. Most likely, this is due to the beginning of active water exchange with the more saline Sea of Marmara, which, due to the system of Black Sea currents, spreads along the shores of Turkey, Georgia and reaches the waters of the Black Sea coast of Russia.

Table 4. Statistical values of monthly distribution of salinity in $49 \mathrm{~m}$ depth.

\begin{tabular}{|c|c|c|c|c|c|c|c|c|c|c|c|c|}
\hline & Jan & Feb & Mar & Apr & May & Jun & Jul & Aug & Sep & Oct & Nov & Dec \\
\hline Min & 17.82 & 17.86 & 17.96 & 18.08 & 18.21 & 18.20 & 18.18 & 18.13 & 18.13 & 18.09 & 18.1 & 18.01 \\
\hline 1-st quartile & 18.50 & 18.47 & 18.48 & 18.49 & 18.55 & 18.62 & 18.63 & 18.64 & 18.61 & 18.58 & 18.59 & 18.57 \\
\hline Median & 18.71 & 18.66 & 18.63 & 18.64 & 18.66 & 18.68 & 18.71 & 18.73 & 18.71 & 18.73 & 18.76 & 18.75 \\
\hline 3-rd quartile & 18.86 & 18.82 & 18.77 & 18.75 & 18.73 & 18.74 & 18.77 & 18.79 & 18.81 & 18.85 & 18.85 & 18.87 \\
\hline Max & 20.38 & 20.26 & 20.43 & 20.79 & 20.83 & 21.13 & 21.52 & 21.74 & 21.77 & 21.12 & 20.95 & 20.62 \\
\hline
\end{tabular}

In general, the distribution of salinity in this depth is significantly less than in the previous ones and ranges from 17 to $21.5 \%$. It should also be noted that there is no occurring of any desalination effect of large rivers in the west, which indicates a weak effect of surface water circulation here.

\section{Conclusion}

Based on conducted research we can state, that:

Spatial distribution of the salinity in the Black Sea has a seasonal structure in all of the upper layers; 
Statistically, the most fluctuated layer is a top layer (up to $2.8 \mathrm{~m}$ ) due to the active flow from Turkish and Ukrainian rivers in north-west and southern parts of the sea. The highest values Black Sea salinity reaches near the Bosporus Strait, where more saline water from the Sea of Marmara connected with fresher water of the Black Sea.

The impact of the river flows, mixing of the water, water regime of the sea decreasing with depth, so in the bottom of the upper layer the spatial fluctuation of the salinity is minimal and reaches about $\pm 3 \%$, while in the depth of $2.8 \mathrm{~m}$ its reaches $\pm 12-15 \%$.

The lowest level of salinity through all of the upper layer $(0-50 \mathrm{~m})$ lays around the seashore and north-western part of the sea. It's explained due to the fact of the Black Sea current system, that has a circular structure and reaches around the sea shore.

\section{References}

1. V. N. Belokopytov and I. G. Shokurova, 12 (2005)

2. D. O. Krivoguz and R. V. Borovskaya, Monit. Syst. Environ. 13 (2020)

3. D. Krivoguz and L. Bespalova, Russ. J. Earth Sci. 20, 1 (2020)

4. P. A. Balykin, D. N. Kutsyn, and A. M. Orlov, Oceanology 59, 358 (2019)

5. T. Kijewski, M. Zbawicka, J. Strand, H. Kautsky, J. Kotta, M. Rätsep, and R. Wenne, Oceanologia 61, 131 (2019)

6. N. G. Sergeeva, N. V. Shadrin, and E. V. Anufriieva, Nematology 21, 337 (2019)

7. M. Ercanoglu, Nat. Hazards Earth Syst. Sci. 5, 979 (2005)

8. V. A. Ivanov and V. N. Belokopytov, Oceanography of the Black Sea (Sevastopol, 2011)

9. $\quad$ V. E. Zaika, Mar. Ekol. J. 5 (2014)

10. V. M. Peshkov, Ecol. Saf. Coast. Shelf Zo. Sea 1, 12 (2015)

11. O. M. Murărescu and G. Pehoiu, WSEAS Trans. Environ. Dev. 6, 85 (2010)

12. K. Rokni, A. Ahmad, A. Selamat, and S. Hazini, Remote Sens. 6, (2014)

13. L. Lima, S. Masina, S. A. Ciliberti, E. L. Peneva, S. Cretí, L. Stefanizzi, R. Lecci, F. Palermo, G. Coppini, N. Pinardi, and A. Palazov, (2020) 